\title{
Correction to: Charcot-Leyden Crystals in Eosinophilic Inflammation: Active Cytolysis Leads to Crystal Formation
}

\author{
Shigeharu Ueki ${ }^{1}$ Yui Miyabe ${ }^{1,2} \cdot$ Yohei Yamamoto $^{3} \cdot$ Mineyo Fukuchi $^{1} \cdot$ Makoto Hirokawa $^{1} \cdot$ Lisa A. Spencer ${ }^{4}$. \\ Peter F. Weller ${ }^{5}$
}

Published online: 13 July 2019

(C) Springer Science+Business Media, LLC, part of Springer Nature 2019

\section{Correction to: Current Allergy and Asthma Reports (2019) 19:35 https://doi.org/10.1007/s11882-019-0868-0}

The original version of this article incorrectly listed the third author's name. It should be Yohei Yamamoto, not Yamamoto Yohei.

The original article has been corrected.

Publisher's Note Springer Nature remains neutral with regard to jurisdictional claims in published maps and institutional affiliations.

The online version of the original article can be found at https://oi.org/ $10.1007 / \mathrm{s} 11882-019-0868-0$

\section{Shigeharu Ueki}

ueki-shige@nifty.com

1 Department of General Internal Medicine and Clinical Laboratory Medicine, Akita University Graduate School of Medicine, 1-1-1, Hondo, Akita 010-8543, Japan

2 Department of Otorhinolaryngology, Head \& Neck Surgery, Akita University Hospital, Akita, Japan

3 Department of Molecular Pathology and Tumor Pathology, Akita University Graduate School of Medicine, Akita, Japan

4 Department of Pediatrics, University of Colorado School of Medicine, Denver, CO, USA

5 Divisions of Allergy and Inflammation and Infectious Diseases, Department of Medicine, Beth Israel Deaconess Medical Center, Harvard Medical School, Boston, MA, USA 